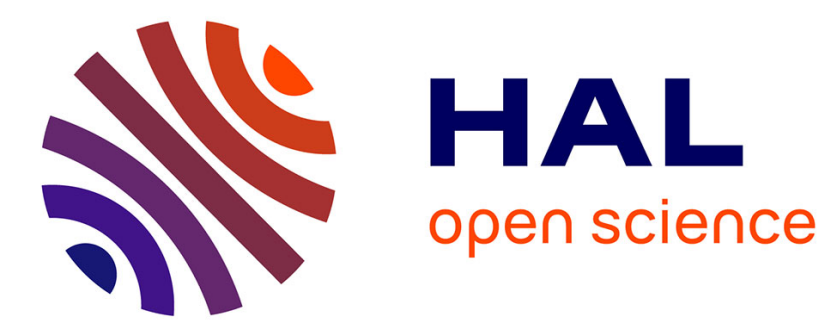

\title{
Observations by DEMETER of man-made MF waves escaping from the ionosphere
}

\author{
Michel Parrot
}

\section{To cite this version:}

Michel Parrot. Observations by DEMETER of man-made MF waves escaping from the ionosphere. Journal of Geophysical Research Space Physics, 2021, 126 (3), pp.e2020JA028954. 10.1029/2020JA028954 . insu-03129647

\section{HAL Id: insu-03129647 https://hal-insu.archives-ouvertes.fr/insu-03129647}

Submitted on 3 Feb 2021

HAL is a multi-disciplinary open access archive for the deposit and dissemination of scientific research documents, whether they are published or not. The documents may come from teaching and research institutions in France or abroad, or from public or private research centers.
L'archive ouverte pluridisciplinaire HAL, est destinée au dépôt et à la diffusion de documents scientifiques de niveau recherche, publiés ou non, émanant des établissements d'enseignement et de recherche français ou étrangers, des laboratoires publics ou privés. 


\section{Observations by DEMETER of man-made MF waves escaping from}

\section{the ionosphere}

by

M. Parrot

LPC2E/CNRS, 3A Avenue de la Recherche Scientifique, 45071 Orléans cedex 2, France and

Université d'Orléans, Avenue du Parc Floral, BP 6749, 45067 Orléans cedex 2, France

Key points :

- DEMETER observed MF waves due to man-made activities above the topside ionosphere when the ionospheric density is anomalously low

- The observations are mainly related to the ionospheric trough region

- These observations also occur in the South Atlantic Anomaly and during high magnetic activity

Abstract : DEMETER was a low altitude satellite on a polar and circular orbit devoted to the study of ionospheric perturbations in relation with seismic activity. Its scientific payload with waves and plasma measurements also allows to study man-made waves. The aim of this paper is to check the conditions of apparition of these man-made waves in the MF range $(300 \mathrm{kHz}$, $3 \mathrm{MHz}$ ). These waves normally propagate in the Earth-ionosphere waveguide but it is shown that they can escape above the ionosphere when there is a decrease in the electron density. This article has been accepted for publication and undergone full peer review but has not been through the copyediting, typesetting, pagination and proofreading process, which may lead to differences between this version and the Version of Record. Please cite this article as doi: 10.1029/2020JA028954.

This article is protected by copyright. All rights reserved. 
This meanly occurs at the ionospheric troughs when they are close to inhabited areas but also above the South Atlantic Anomaly and when the magnetic activity is high.

Plain Language Summary: The aim of the micro-satellite DEMETER (660 km altitude) was devoted to the study of ionospheric anomalies which could be related to earthquake preparation. But its scientific payload which was composed of wave, particle, and density experiments also allows the survey of the Earth's environment. In this work we have performed a systematic study of man-made waves which are observed by the satellite in the MF range $(300 \mathrm{kHz}-3 \mathrm{MHz})$. Normally these waves, which are mainly used for radio navigation and broadcasting, propagate in the waveguide formed by the Earth's surface and the bottom of the ionosphere, but bursts of these waves are observed above inhabited areas when the ionospheric density is anomalously low. This occurs under three conditions: i) when the satellite is close to the mid-latitude ionospheric trough, ii) in the area of the South Atlantic Magnetic Anomaly where the Earth's magnetic field is lower than anywhere else, and iii) when the magnetic activity is high. Then these waves can propagate in the magnetosphere and interact with natural waves.

Key words: ionosphere, man-made MF waves, ionospheric trough

\section{Introduction}

Man-made Medium Frequency (MF) waves are in a frequency range between $300 \mathrm{kHz}$ and $3 \mathrm{MHz}$. They are typically used by broadcasting, radio-navigation (maritime and aeronautical), and maritime mobile communications. They propagate in the Earth-ionosphere waveguide [Milsom, 2003]. Normally they are reflected and cannot cross the ionosphere because their frequencies are lower than the plasma frequency in the $\mathrm{F}$ layer. But there is a 
possibility for these waves to cross the ionosphere if they follow a magnetic field line. Individual observations of broadcast transmitters above the $\mathrm{F}$ layer have been already done [LaBelle et al., 1989; Kaiser et al., 1996; Kelley et al., 1997; Hashimoto et al., 2018]. Concerning the low altitude satellite DEMETER, if the recorded MF spectra are averaged over a large time interval, the transmitter locations appear on a terrestrial map of wave activity as hot spots which are a little bit shifted equatorwards due to their propagation along a magnetic field line [Füllekrug et al., 2009; Parrot, 2018; Nagy et al., 2018].

MF man-made waves also appear in DEMETER MF spectrograms at very different locations and the purpose of this paper is to systematically study all bursts of man-made waves which emerge from time to time in these MF spectrograms. The DEMETER data are briefly described in Section 2. Various events are shown in Section 3. Discussions and conclusions are given in Sections 4 and 5, respectively.

2. The data

DEMETER was in operation between 2004 and 2010 on a polar and circular sunsynchronous orbit with an altitude of $710 \mathrm{~km}$ (decreased to $660 \mathrm{~km}$ in 2005). Among the different experiments of the scientific payload there was an electric field experiment to continuously measure onboard the satellite the electric field spectrum up to $3.33 \mathrm{MHz}$ with a frequency resolution of $3.25 \mathrm{kHz}$ and a time resolution of $2.048 \mathrm{~s}$ [Berthelier et al., 2006]. The electron density was in situ measured by a Langmuir probe [Lebreton et al., 2006]. Due to technical reasons data are only recorded at invariant latitudes less than $65^{\circ}$ except for specific campaigns in relation with HAARP or EISCAT. All data files and plots are organised by half-orbits [Lagoutte et al., 2006]. In this paper, the up-going half-orbits corresponding to night time (22:30 LT) are only used because the ionospheric electron density is too high 
during day time to observe MF waves coming from below. A total of 28710 night time halforbits have been checked.

\section{The observations}

The top panel of Figure 1 shows the MF spectrogram of an electric field component recorded on 24 September 2006 during 4 minutes. One can see a set of frequency lines over a large frequency range between 0.6 and $1.6 \mathrm{MHz}$. The intensity of some frequency lines is very important $\left(0.3 \mu \mathrm{V}^{2} \cdot \mathrm{m}^{-2} \cdot \mathrm{Hz}^{-1}\right)$ as it is of the order of the wave intensity in the VLF range $(<20 \mathrm{kHz})$. The spectrogram is recorded above Canada and the observed frequency lines correspond to emissions from various transmitters at different frequencies because the MF band has been shared between many different users. The bottom panel of Figure 1 displays the electron density which is lower at the time of the burst of the frequency lines. The density decrease fits well with the apparition of the MF waves. The shape of the electron density decrease (slow in the equatorward direction and sharp in the pole ward direction) is typical of the phenomenon called mid latitude ionospheric trough. This ionospheric trough which is a night-side event is well documented since a long time and, at both the F layer and the topside ionosphere, it corresponds to the plasmapause position [see for example, Taylor and Walsh, 1972; Karpachev, 2003; Yizengaw and Moldwin, 2005; Rothkaehl et al., 2008; Grebowsky et al., 2009; He et al., 2011; Chen et al., 2018; Karpachev et al., 2019].

Figure 2 is similar to Figure 1 but the data are recorded on $3^{\text {rd }}$ August 2008 in a region close to the equator. One can see that the apparition of the MF waves also corresponds to a decrease of the electron density. This electron density is anomalously low at this location because we are at the end of the non-typical solar cycle 23 where the $\mathrm{F} 10.7 \mathrm{~cm}$ solar flux was very low. 
A third event different from the two others is shown in Figure 3. It was recorded on 8 November 2008, a day of moderate magnetic activity with Dst $=-17 \mathrm{nT}$ and $\mathrm{kp}=3.3$. The electron density in the bottom panel presents plasma depletions which are simultaneous with the apparition of bursts of frequency lines in the top panel.

A fourth example is shown in Figure 4 where the data are recorded on 15 December 2006 at the time of high magnetic activity (Dst $=-156 \mathrm{nT}, \mathrm{kp}=7.7$ ). This corresponds to a rare half-orbit where we have at the beginning of the plot an event due to the magnetic activity with a dramatic decrease of the density as in Figure 3, and at the end of the plot an event related to an ionospheric trough as in Figure 1. One can notice that the two frequency bands are different because the satellite is not above the same countries (close to Peru around 03.51.40 UT and above USA around 04.06.00 UT).

\section{Discussions}

All in all we have observed 1066 events related to the trough (of which only 184 are in the South hemisphere), 85 events related to an anomalous low density, and 29 events related to a high magnetic activity. The locations of all these events are displayed in Figure 5 with symbols of different colors. The events related to the trough (black symbol) are observed at mid and high latitudes. They also correspond to inhabited areas where MF transmitters are located but there are some unexplained gaps close to the South Africa and the South America which will be discussed later on. It is remarkable to see that the events related to low density (green symbol) are mainly located in the South Atlantic Magnetic Anomaly (SAMA). One can also say that these events are recorded during winter time in the South hemisphere which contributes to the decrease of the electron density together with low F10.7cm solar flux in the decreasing part of the solar cycle 23. A second set of green symbols is located in the Indian 
Ocean at the magnetic equator. The high magnetic activity events (red symbol) do not have particular locations.

We cannot have all trough locations in our database because we have a limitation in latitude and we only record MF events close to inhabited areas where man made waves can be observed. But it is interesting to check the evolution of the detected troughs as function of the time. This is done in Figure 6 where the $\mathrm{L}$ values of the trough positions in the North hemisphere are shown as function of the years ( $\mathrm{L}$ is the Mcllwain parameter). Several points can be underlined: i) there is a large variability of the trough positions, ii) the troughs are mainly detected during winter time, and iii) there is a trend as the L values increases with the time. This last variation is related to the decreasing part of the solar cycle 23 because it is known that the trough positions move to lower latitudes when the geomagnetic activity increases [Rothkaehl et al., 2008; Chen et al., 2018]. This is well illustrated in Figure 4 where the geographic latitude of the trough is around $36^{\circ}$.

As it was noticed before, we only observe a very few number of events close to the South Africa and the South America in Figure 5. This is due to the position of the trough in the South hemisphere. It has been shown (see Figure 3 of Chen et al., 2018) that the trough is at latitudes much higher than the inhabited area latitudes except for Australia and New Zealand. Then even if there are emissions of MF waves in South Africa, Chile and Argentina they cannot be observed because the locations of these emissions are too far from the trough position. However we have a few events and the MF event located at lat $=-67.6^{\circ}$ and long $=$ $270.7^{\circ}$ is displayed in Figure 7 as example. Data from a complete half-orbit are shown in this Figure. One can see in the top panel the two MF emissions observed in the South hemisphere at $\sim 05.17 .00$ UT and in the North hemisphere at $\sim 05.50 .30$ UT. They both correspond to a trough position indicated by the electron density in the bottom panel. But the emissions observed above the South Pacific Ocean are far from the South American continent, and then, 
they cannot be attributed to MF transmitters located in Chile or Argentina. As the trough corresponds to the plasmapause at higher altitudes it has been shown by Blagoveshchensky et al. [1997] that this plasmapause could be a waveguide for the MF waves. Therefore these emissions observed above the South Pacific Ocean must come from the magnetically conjugate region in the other hemisphere which is in Canada (close to lat $=44.25^{\circ}$, long $=$ $280.33^{\circ}$ ). In Figure 7, the other MF emission observed at $\sim 05.50 .30$ UT in the North hemisphere is also recorded above Canada. It can be noticed that they have a very similar frequency band, and that, due to the propagation, the MF emission in the South hemisphere have lower amplitude than the MF emission in the North hemisphere. Two other points must be underlined concerning this event in Figure 7: (i) the data are recorded during a period of moderate magnetic activity (Dst $=-51 \mathrm{nT}, \mathrm{kp}=6.0$ ) which means that the positions of the trough are not usual, and (ii) to observe the MF emission coming from above the satellite a plasma depletion is additionally needed. Concerning the observations just close to the New Zealand in Figure 5 it also means that all these events are certainly not due to transmitters located in this country but a small part could be related to emissions in the North hemisphere because this area is magnetically conjugate to Alaska.

In Figures 1-4 and 7, the electron density is measured at the altitude of the satellite but we do not know the density below. It is possible to obtain a rough value considering that (i) the plasma frequency in $\mathrm{kHz}$ is equal to $9 \mathrm{~N}_{\mathrm{e}}^{1 / 2}$ where the electron density $\mathrm{N}_{\mathrm{e}}$ is in $\mathrm{cm}^{-3}$, and (ii) the MF waves cannot cross the ionosphere if their frequencies are lower than the plasma frequency. For example in Figure 1 the minimum frequency observed in the spectrogram is of the order of $0.6 \mathrm{MHz}$, and this means that the maximum electron density below the satellite is $\sim 4.410^{3} \mathrm{~cm}^{-3}$. This is higher than the minimum density observed at $660 \mathrm{~km}$ in the bottom panel of Figure 1 as expected because in this part of the ionosphere the density decreases when the altitude increases.

This article is protected by copyright. All rights reserved. 


\section{Conclusions}

For the first time an extensive study of the man-made MF waves observed by a low altitude satellite in the top of the ionosphere has been done. It is shown that these waves can escape from the ionosphere at the locations where the electron density is particularly low. There are three possibilities:

- The largest number of events occurs when the satellite is close to the mid-latitude ionospheric trough during winter time. At higher altitudes the trough corresponds to the plasmapause which could be a waveguide for the MF emissions (Blagoveshchensky et al., 1997). Therefore, these MF waves can propagate in the opposite hemisphere as it is the case for the event shown in Figure 7. Concerning their possible influence in the magnetosphere, interaction of man-made MF waves with natural waves at large distances has been revealed by Hashimoto et al. [2018].

- A second set of events is observed in the SAMA and could be related to the very low solar flux at the end of the solar cycle 23.

- The third possibility happens during high magnetic activity periods which produce large and sharp plasma depletions in the ionospheric density.

Acknowledgments: The satellite DEMETER was operated by the French Centre National d'Etudes Spatiales (CNES). This work is based on observations with the electric field experiment ICE and the Langmuir probe experiment ISL embarked on DEMETER. The author thanks J. J. Berthelier and J.P. Lebreton the PIs of these experiments for the use of the data. Many thanks are also due to J.Y. Brochot who was deeply involved in the data handling since the beginning of the mission. The DEMETER data shown in this paper can be obtained 
at https://cdpp-archive.cnes.fr/. The Dst values are from the WDC for geomagnetism in Kyoto.

\section{References}

Berthelier, J.J., et al., (2006), ICE, The electric field experiment on DEMETER, Planet. Space Sci., 54, 456-471.

Blagoveshchensky, D. V., Dobroselsky, K. A., and Maltseva, O. A. (1997). Main ionospheric trough as a channel for MF propagation in the magnetosphere. Radio Science, 32(4), 14771490.

Chen, C. Y., Liu, T. J. Y., Lee, I. T., Rothkaehl, H., Przepiorka, D., Chang, L. C., et al. (2018). The midlatitude trough and the plasmapause in the nighttime ionosphere simultaneously observed by DEMETER during 2006-2009. Journal of Geophysical Research: Space Physics, 123, 5917-5932. https:// doi.org/10.1029/2017JA024840.

Füllekrug, M., et al., (2009), Transionospheric attenuation of $100 \mathrm{kHz}$ radio waves inferred from satellite and ground based observations, Geophys. Res. Lett., 36, L06104, doi:10.1029/2008GL036988.

Grebowsky, J. M., Benson, R. F., Webb, P. A., Truhlik, V., and D. Bilitza (2009). Altitude variation of the plasmapause signature in the main ionospheric trough. Journal of Atmospheric and Solar-Terrestrial Physics, 71(16), 1669-1676.

Hashimoto, K., Kumamoto, A., Tsuchiya, F., Kasahara, Y., and A. Matsuoka (2018). Hectometric line spectra detected by the Arase (ERG) satellite. Geophys. Res. Lett., 45, 11,555-11,561. https://doi.org/10.1029/2018GL080133

He, M., L. Liu, W. Wan, and B. Zhao (2011), A study on the nighttime midlatitude ionospheric trough, J. Geophys. Res., 116, A05315, doi:10.1029/2010JA016252. 
Kaiser, M. L., M. D. Desch, J.-L. Bougeret, R. Manning, and C. A. Meetre (1996), WIND/WAVES observations of man $\square$ made radio transmissions, Geophys. Res. Lett., 23(10), 1287-1290, doi:10.1029/95GL03665.

Karpachev, A.T. (2003), The dependence of the main ionospheric trough shape on longitude, altitude, season, local time, and solar and magnetic activity, Geomagn. Aeron., 43(2), 239251.

Karpachev, A. T., Klimenko, M. V., and V.V. Klimenko (2019). Longitudinal variations of the ionospheric trough position. Advances in Space Research, 63(2), 950-966.

Kelley, M. C., S. D. Baker, R. H. Holzworth, P. Argo, and S. A. Cummer (1997), LF and MF observations of the lightning electromagnetic pulse at ionospheric altitudes, Geophys. Res. Lett., 24(9), 1111-1114.

LaBelle, J., Treumann, R. A., Boehm, M. H., and K. Gewecke (1989). Natural and man $\square$ made emissions at 1.0-5.6 MHz measured between 10 and $18 \mathrm{RE}$. Radio Science, 24(6), 725-737. Lagoutte, D., et al. (2006), The DEMETER science mission centre, Planet. Space Sci., 54, $428-440$.

Lebreton, J. P., et al. (2006), The ISL Langmuir Probe experiment and its data processing onboard DEMETER: Scientific objectives, description and first results, Planet. Space Sci., 54, 472 - 486, doi:10.1016/ j.pss.2005.10.017.

Milsom, J. (2003), Surface waves, and sky waves below $2 \mathrm{MHz}$ in Propagation of radio waves ( $2^{\text {nd }}$ edition), Barclay, L. (Ed.), The Institution of Electrical Engineers, London, UK, pp 357-383.

Nagy, M., Steinbach, P., and J. Lichtenberger (2018). What are the sources of MF signatures recorded on DEMETER satellite? In 2018 2nd URSI Atlantic Radio Science Meeting (ATRASC) (pp. 1-4). IEEE. 
Parrot, M. (2018). DEMETER observations of man-made waves that propagate in the ionosphere, Comptes Rendus Physique, 19(1-2), 26-35.

Rothkaehl, H., Krakowski, A., Stanislawska, I., Błęcki, J., Parrot, M., Berthelier, J. J., and J.P. Lebreton (2008). Wave and plasma measurements and GPS diagnostics of the main ionospheric trough as a hybrid method used for Space Weather purposes. Annales Geophysicae, European Geosciences Union, 26 (2), 295-304.

Taylor, H.A. and W.J. Walsh (1972), The light ion trough, the main trough and the plasmapause, J. Geophys. Res., 77(34), 6716-6723.

Yizengaw, E. and M.B. Moldwin (2005), The altitude extension of the mid-latitude trough and its correlation with plasmapause position, Geophys. Res. Lett., 32, L09105, doi:10.1029/2005GL022854.

This article is protected by copyright. All rights reserved. 


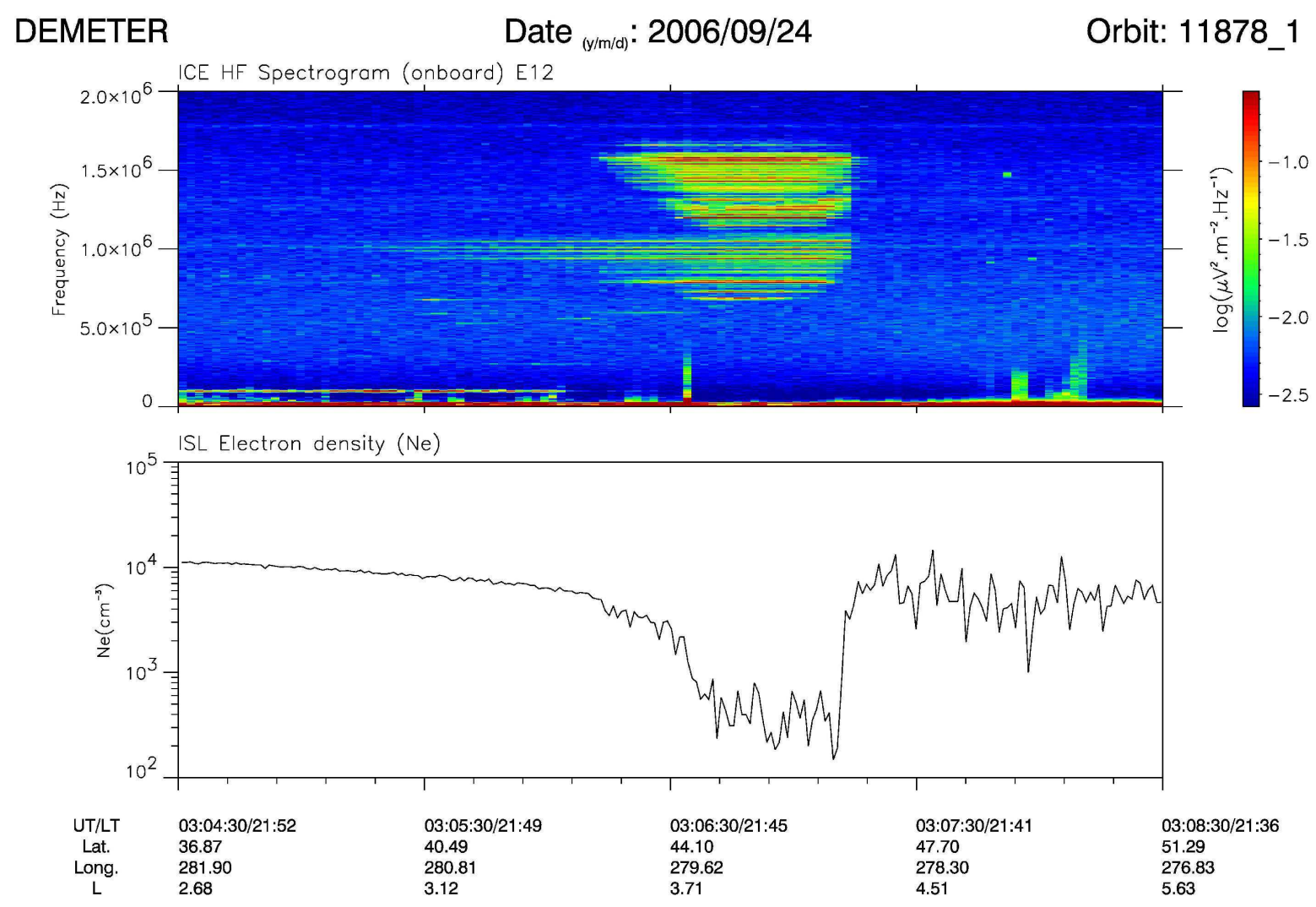

Figure 1: (top panel) MF spectrogram up to $2 \mathrm{MHz}$ onboard recorded on 24 September 2006 between 03:04:30 and 03:08:30 UT. The power spectral density is color-coded according to the scale on the right. (bottom panel) Electron density in situ recorded during the same period. The parameters below the panels indicate the Universal Time, the Local Time, the geographical latitude and longitude, and the McIlwain parameter L.

This article is protected by copyright. All rights reserved. 
DEMETER Date ${ }_{(y / m / d)}: 2008 / 08 / 03 \quad$ Orbit: 21850_1
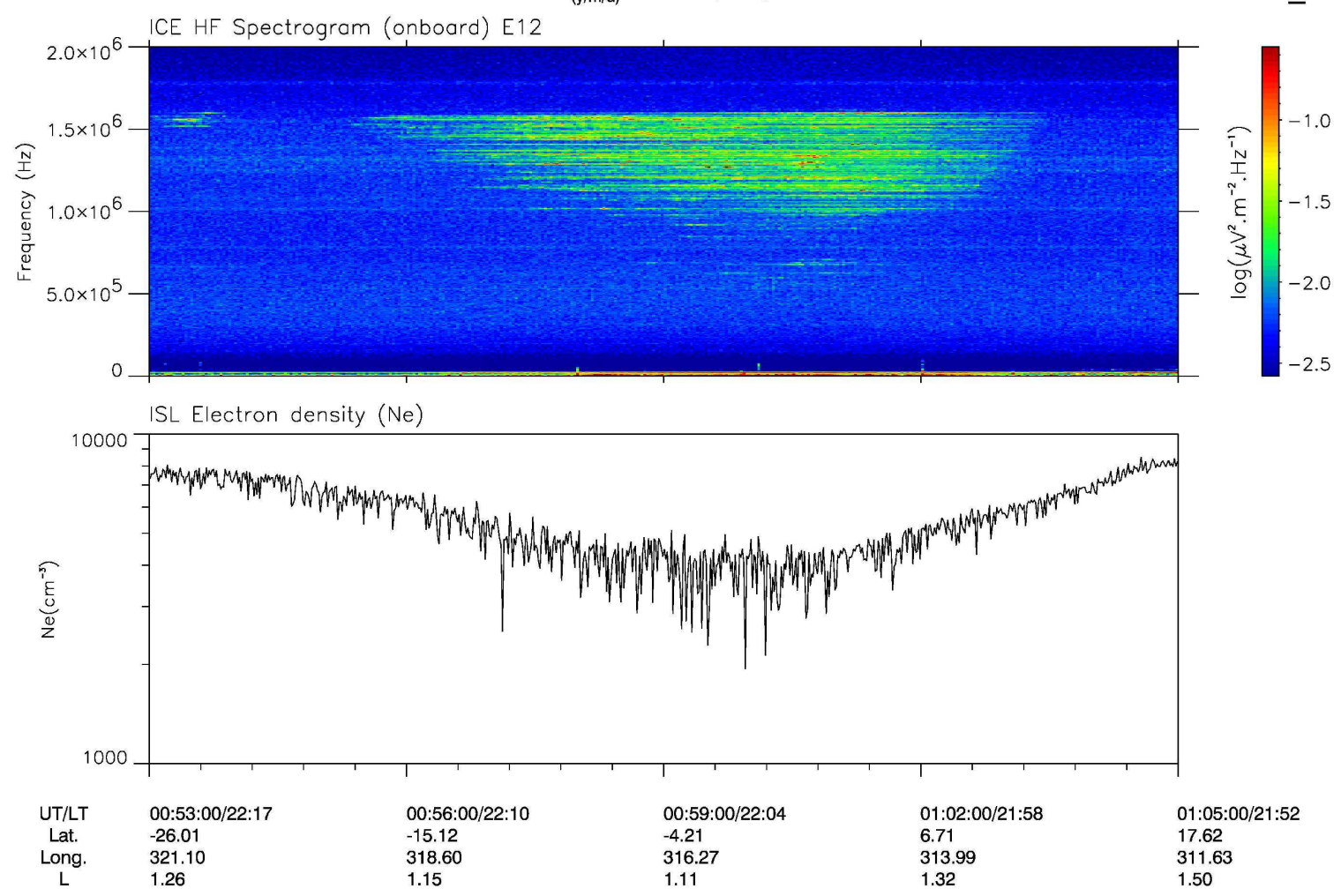

Figure 2: Same as Figure 1 but for data recorded on $3^{\text {rd }}$ August 2008 between 00:53:00 and 01:05:00 UT.

This article is protected by copyright. All rights reserved. 
DEMETER Date ${ }_{(y / \mathrm{m} / \mathrm{d})}: 2008 / 11 / 08$

Orbit: $23277 \_1$
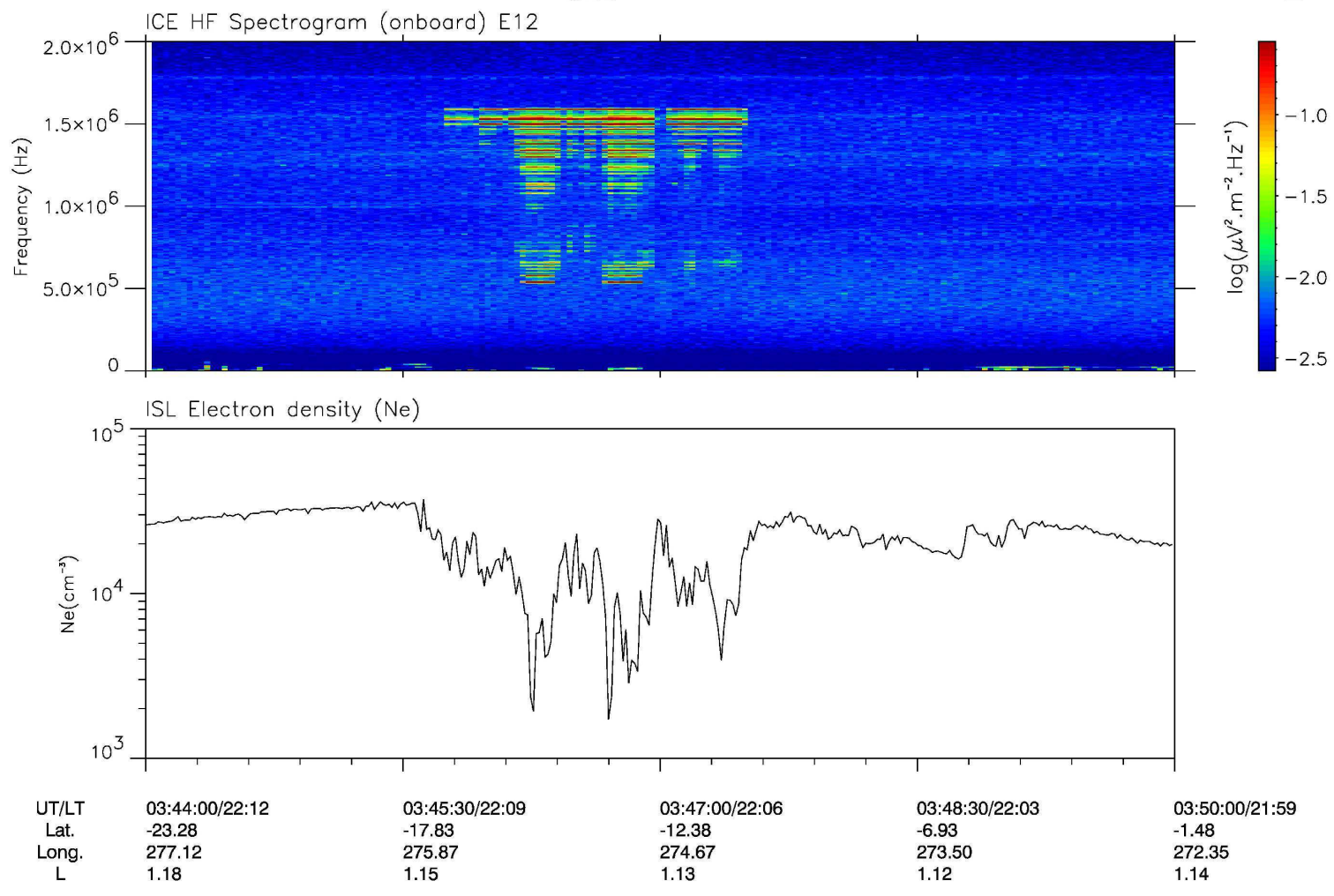

Figure 3: Same as Figures 2 and 3 but for data recorded on 8 November 2008 between 03:44:00 and 03:50:00 UT.

This article is protected by copyright. All rights reserved. 
DEMETER Date ${ }_{(y / \mathrm{m} / \mathrm{d})}: 2006 / 12 / 15$

Orbit: $13083 \_1$
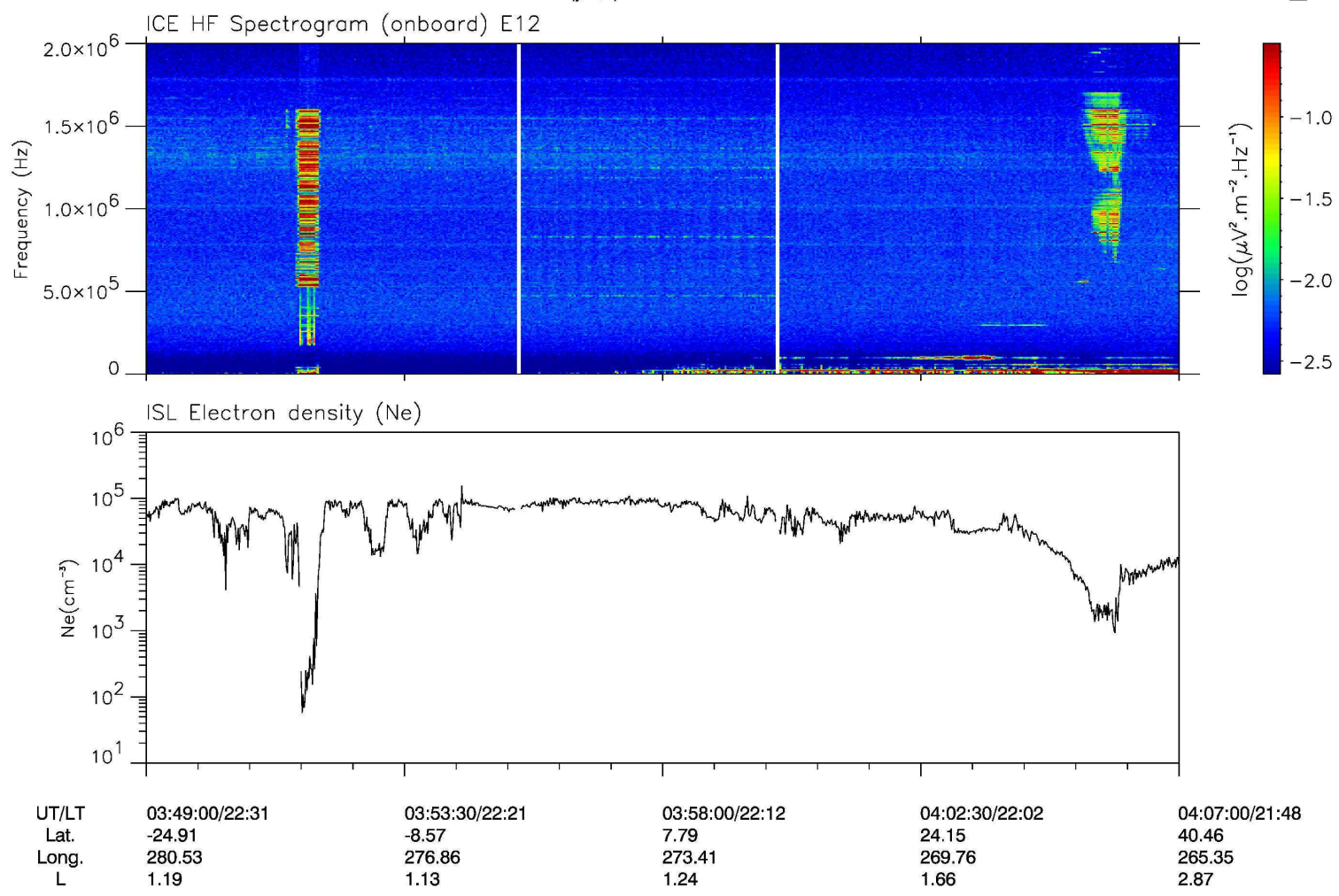

Figure 4: Same as Figures 1, 2 and 3 but for data recorded on 15 December 2006 between 03:49:00 and 04:07:00 UT. The two white lines in the spectrogram correspond to a lack of data.

This article is protected by copyright. All rights reserved. 


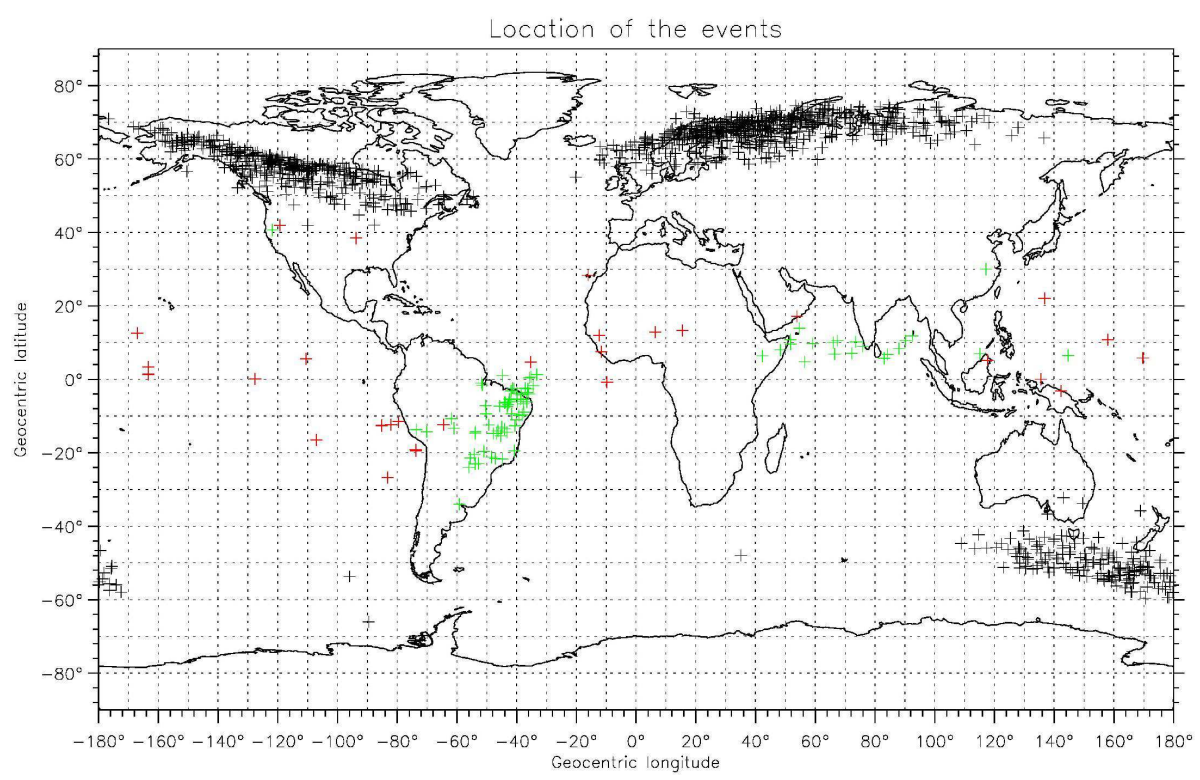

Figure 5 : Global map of the location of the events. The black signs + are related to positions of the ionospheric trough. The green signs + correspond to ionospheric density decrease. The red signs + are associated to periods of high magnetic activity.

This article is protected by copyright. All rights reserved. 


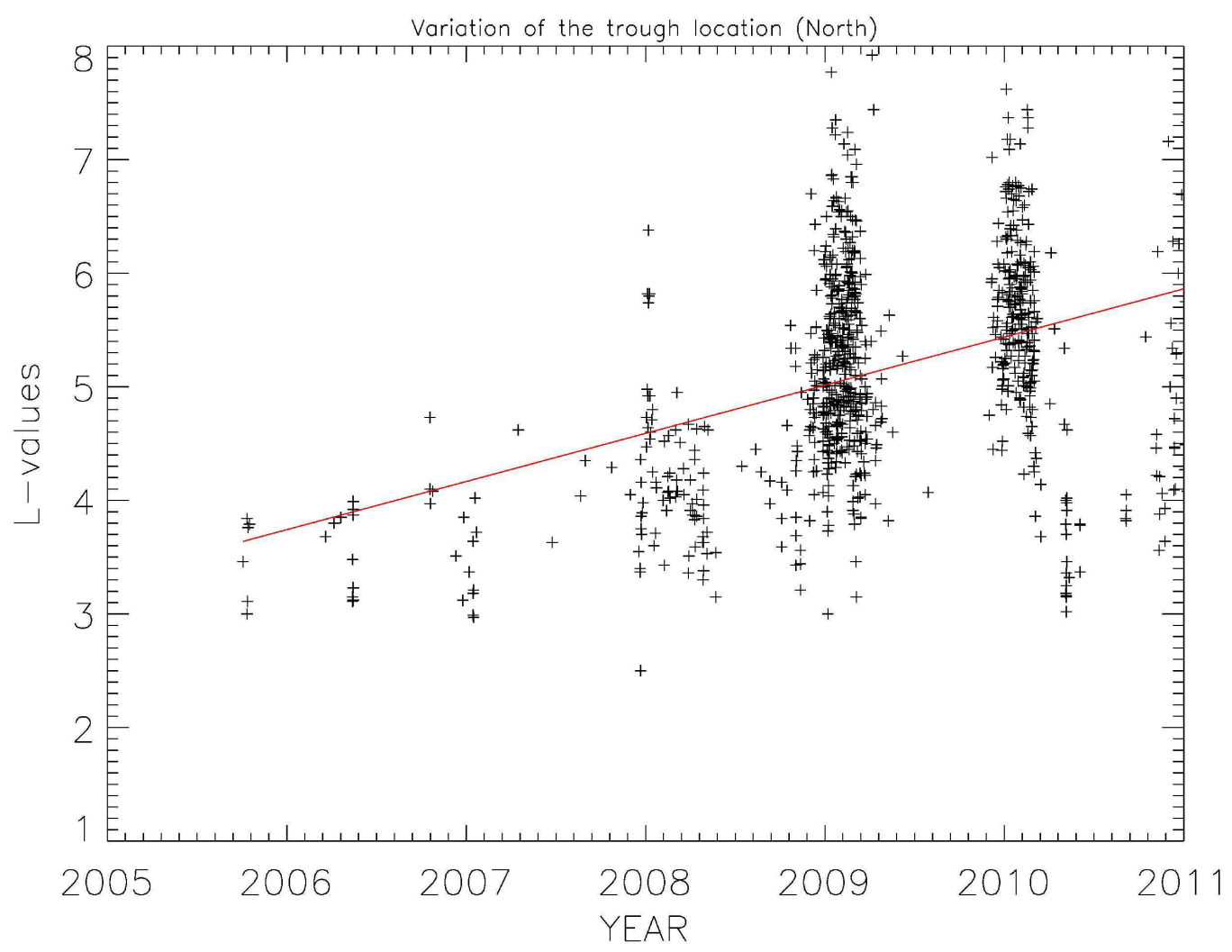

Figure 6: L-values of the troughs where MF waves are observed as function of the time. Only the events in the North hemisphere are considered. The red line is a linear fit of the data.

This article is protected by copyright. All rights reserved. 
DEMETER Date ${ }_{(y / m / d)}: 2008 / 09 / 04$

Orbit: 22323_1
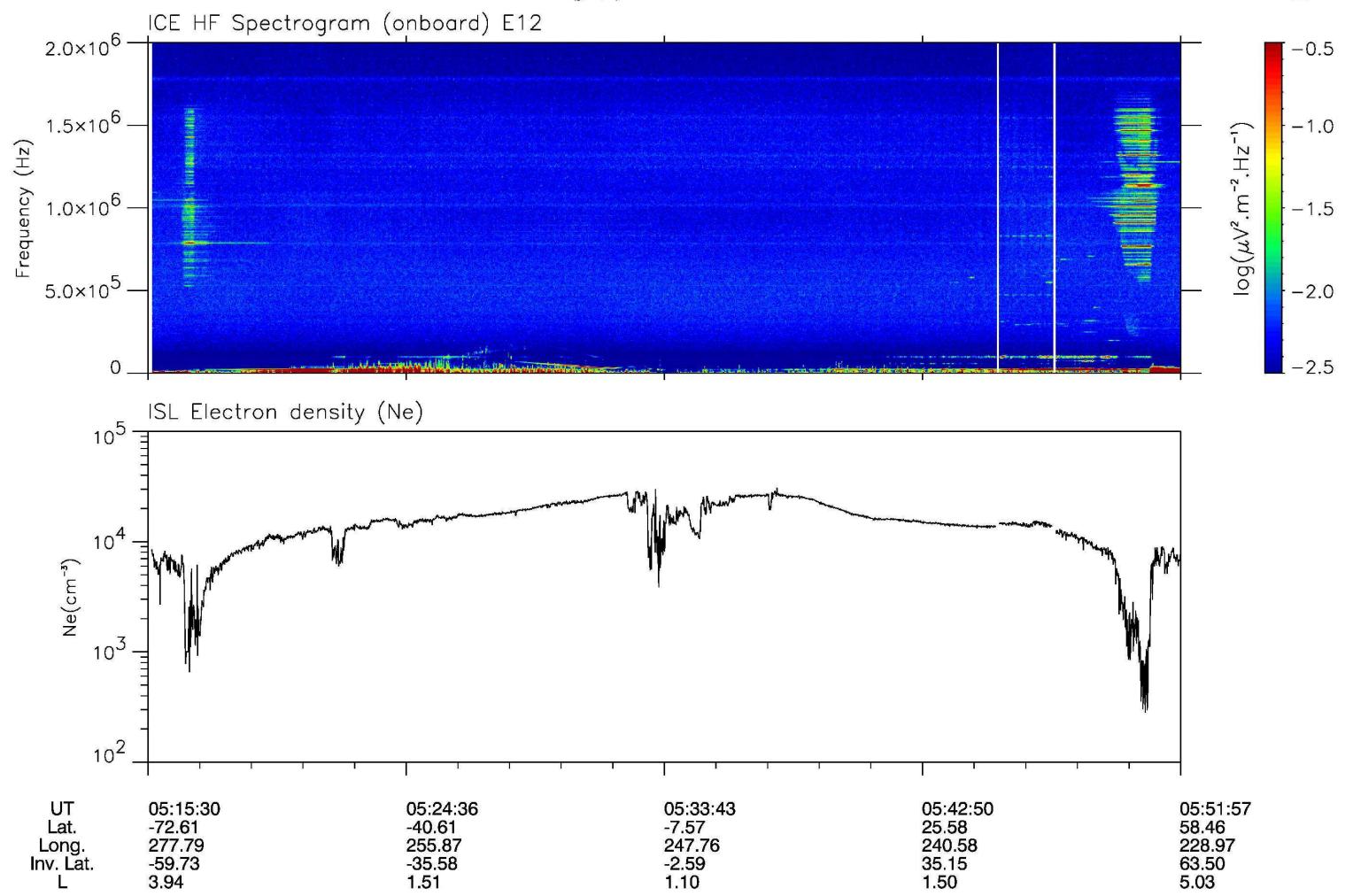

Figure 7: Same as Figures 1-4 but for data recorded on 4 September 2008 between 05:15:30 and 05:51:57 UT. The two white lines in the spectrogram correspond to a lack of data.

This article is protected by copyright. All rights reserved. 